УДК 621.515

О.Н. Щербаков

ПАТ «Сумське НВО ім. М.В. Фрунзе», м. Суми

\title{
МЕТОДИКА ЕКСПЕРИМЕНТАЛЬНОГО ДОСЛІДЖЕННЯ ВДУВА У БЕЗЛОПАТКОВОМУ ДИ- ФУЗОРІ ВІДЦЕНТРОВОГО КОМПРЕСОРА
}

У статті викладена методика експериментального дослідження вдува у безлопатковому дифузорі відиентровго компресора на аеродинамічному стенді. Наведено опис експериментальної установки, засобів вимірювання, викладена методика обробки дослідних даних.

Ключові слова: Відиентровий компресор - Експериментальне дослідження - Безлопатковий дифузор - Розширення діапазону усталеної роботи .

\section{О.Н. Щербаков}

ПАО «Сумское НПО им. М.В. Фрунзе», г. Сумыл

\section{МЕТОДИКА ЭКСПЕРИМЕНТАЛЬНОГО ИССЛЕДОВАНИЯ ВДУВА В БЕЗЛОПАТОЧНОМ ДИФФУЗОРЕ ЦЕНТРОБЕЖНОГО КОМПРЕССОРА}

В статье изложена методика экспериментального исследования вдува в безлопаточном диффузоре иентробежного компрессора на аэродинамическом стенде. Дань описание экспериментальной установки, средств измерения, изложена методика обработки опытных данныхх.

Ключевые слова: Центробежный компрессор - Экспериментальное исследование Безлопаточный диффузор - Расширение диапазона устойчивой работы

\author{
O.N. Shcherbakov \\ PJSC Sumy Frunze NPO, Sumy
}

\section{PROCEDURE OF EXPERIMENTAL RESEARCH OF INJECTION IN THE VANELESS DIFFUSER OF CENTRIFUGAL COMPRESSOR}

Procedure of experimental research of injection in the vaneless diffuser of centrifugal compressor is presented in the paper. The test rig, measuring system and calculation procedure are described.

Keywords: Centrifugal compressor - Experimental investigation - Vaneless diffuser - Extending of the stable operating range.

\section{I. ВВЕДЕНИЕ}

В области малых производительностей диапазон устойчивой работы центробежных компрессоров ограничен режимом возникновения помпажа. Возникающие при помпаже колебания расхода и давления газа вызывают повышенные нагрузки на ротор и подшипники машины, что может привести к их разрушению. Поэтому расширение диапазона устойчивой работы является важной научнотехнической задачей.

Большинство исследователей $[1,2,3]$ связывают возникновение помпажа с образованием внутри проточной части развитых отрывных течений. Поэтому для расширения диапазона устойчивой работы целесообразно использовать способы управления отрывом потока, одним из которых является вдув.

В последнее время появился ряд публикаций, посвященных способам расширения диапазона устойчивой работы осевых и центробежных компрессоров за счет вдува. Так Нельсон и др. [4] про- демонстрировали эффект вывода осевого компрессора газотурбинного двигателя из зоны помпажа с помощью вдува через отверстия, выполненные на поверхностях лопаток направляющего аппарата со стороны разряжения. Штейн и др. [5] численно промоделировали течение в высокоскоростном центробежном колесе, работающем в области помпажа. Авторы также исследовали влияние вдува на входе в рабочее колесо. Было установлено, что вдув предотвращает местный отрыв потока, который провоцирует масштабные обратные течения, благодаря чему повышается устойчивость работы. Шпаковски и др. [6] и Скоч [7] экспериментально продемонстрировали возможность расширения диапазона устойчивой работы центробежной ступени путем вдува в безлопаточном участке между рабочим колесом и канальным диффузором. При этом оба автора отмечали, что вдув приводит к потерям энергии и снижает эффективность работы ступени.

Несмотря на то, что количество исследований, посвященных способам расширения диапазона устойчивой работы центробежных ступеней посте- 
пенно возрастает, вопрос о влиянии вдува в безлопаточном диффузоре (БЛД) остается неосвещенным. В данной работе изложена методика экспериментального исследования вдува в безлопаточном диффузоре центробежного компрессора на аэродинамическом стенде.

\section{II. ЭКСПЕРИМЕНТАЛЬНАЯ УСТАНОВКА. ОБЪЕКТ ИССЛЕДОВАНИЯ}

Экспериментальные исследования проводились на аэродинамическом стенде АД-400 научноисследовательского комплекса ПАО «Сумское НПО им. М.В. Фрунзе». Стенд выполнен по открытой схеме, рабочей средой является воздух. Схема стенда представлена на рисунке 1.

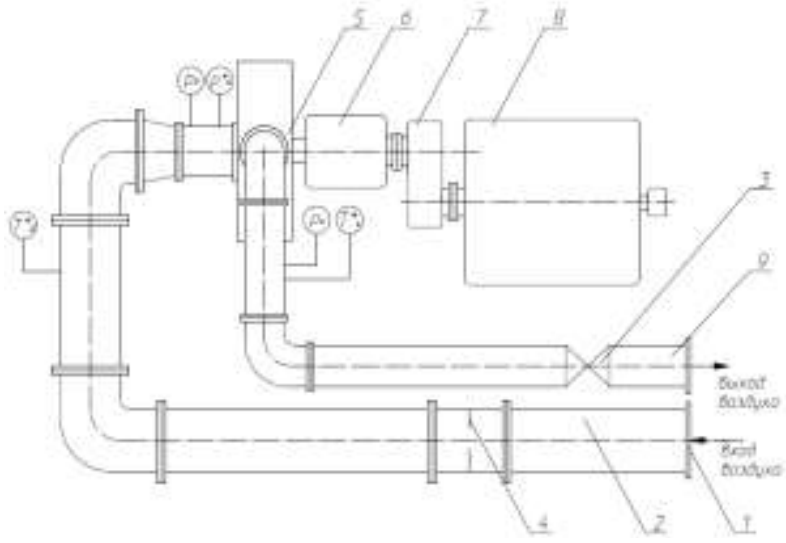

1 - фильтр; 2 - всасывающий трубопровод; 3 регулирующая заслонка; 4 - диафрагма; 5 - экспериментальная модель; 6 - подшипники модели; 7 мультипликатор; 8 - двигатель постоянного тока; 9 - нагнетательный трубопровод

Рисунок 1 - Принципиальная схема аэродинамического стенда

Модельная ступень состояла из рабочего колеса закрытого типа с 11-ю S-образными лопатками (угол выхода лопаток равен $32^{0}$ ) и безлопаточного диффузора с параллельными стенками (рисунок 2).

Для исследования влияния вдува конструкция исходной ступени была доработана (рисунок 3).

Во входном участке диффузора были установлены кольцевые накладки 1, играющие роль соплового аппарата. После установки накладок значение относительной ширины диффузора на входе снизилась до значения $\bar{b}_{3}=0,045\left(b_{3} / b_{2}=0,75\right)$. Относительный наружный диаметр соплового аппарата $\bar{D}_{H}=1,18$. Относительная ширина диффузора за сопловым аппаратом равна относительной ширине диффузора базовой ступени $\bar{b}_{4}=0,065$. На поверхностях накладок, прилегающих к дискам диффузора 2, выполнены проточки, выполняющие функцию сопел. На каждой из накладок выполнено 90 проточек, равномерно расположенных по окружности. Ширина проточек - 4 мм, глубина 1,5 мм. Поскольку градиент давления, вызывающий отрыв пограничного слоя, в безлопаточном диффузоре направлен по радиусу, то с целью максимально сдвинуть отрыв потока в область меньших расходов, сопла были направлены в радиальном направлении.

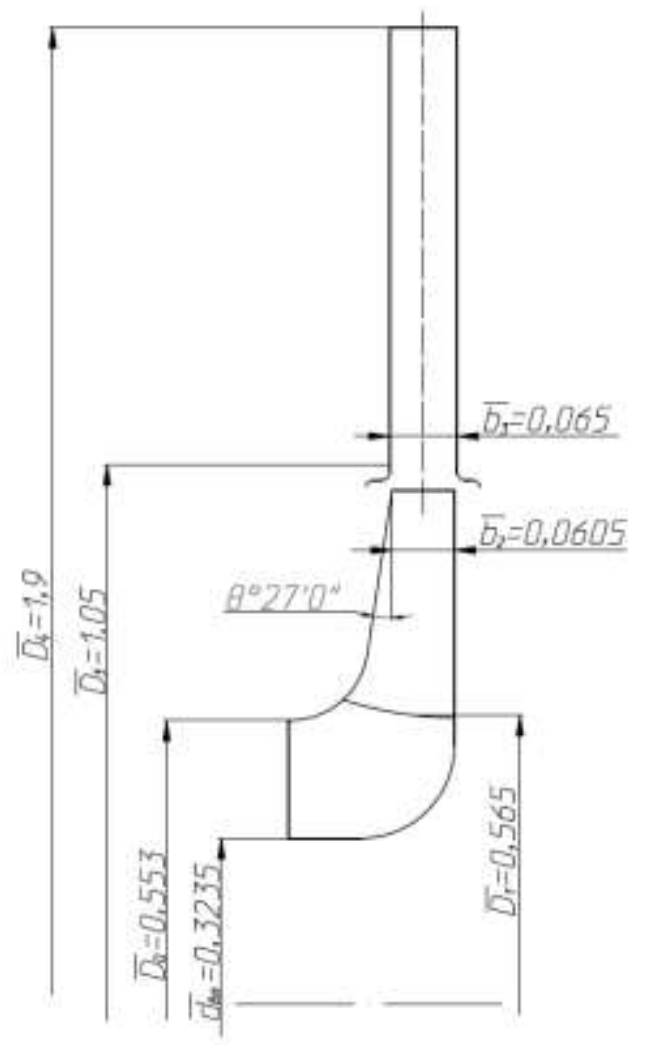

Рисунок 2 - Эскиз меридионального сечения модельной двухзвенной ступени

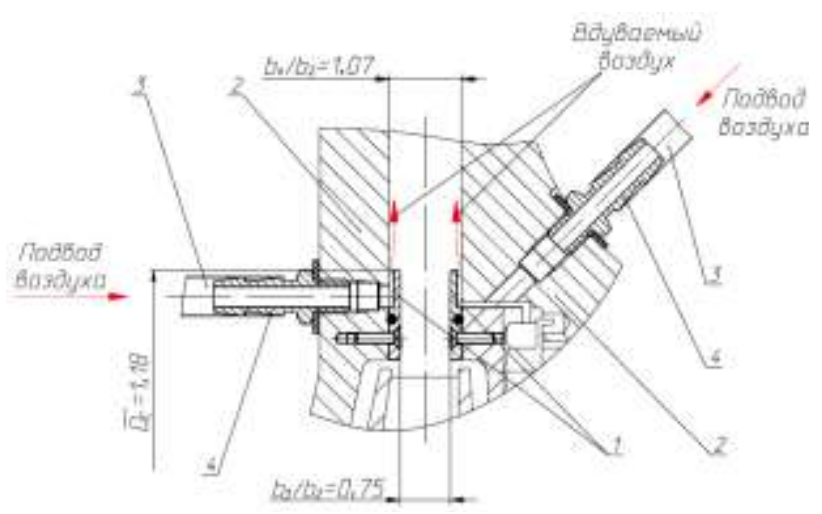

1 - сопловой аппарат; 2 - диск диффузора; 3 - рукав; 4 - штуцер

Рисунок 3 - Конструктивная схема доработанного диффузора

Воздух, используемый для вдува в БЛД, подавался из заводской пневмосети по двум независимым линиям: одна для вдува со стороны основ- 
ного диска диффузора, вторая - со стороны покрывного. Используемая схема позволила исследовать различные варианты вдува со стороны каждого из дисков.

\section{III. КРИТЕРИИ ОЦЕНКИ ЭФФЕКТИВНО- СТИ. ОБРАБОТКА ОПЫТНЫХ ДАННЫХ}

Для оценки эффективности двухзвенной ступени используются политропный КПД $\eta^{*}{ }_{\text {пол }}$ и коэффициента политропного напора $\psi^{*}$ пол, рассчитанные по полным параметрам. В качестве режимного параметра используется условный коэффициент расхода $\Phi_{0}$. Расчет необходимых параметров производится по формулам, представленным в [8].

Термодинамическая температура и средняя скорость на входе в ступень рассчитываются методом последовательных приближений:

$$
\begin{gathered}
T_{0}=T_{0}^{*}-\frac{c_{0 c p}^{2}}{2 \cdot c_{p}} ; \\
c_{0_{c p}}=\frac{\bar{G}}{\rho_{0} \cdot f_{0}} ; \\
\rho_{0}=\frac{p_{0}}{R \cdot T_{0}},
\end{gathered}
$$

где $T_{0}$ - температура на входе в ступень, $K$;

$T^{*}{ }_{0}$ - полная температура на входе в ступень, $K$;

$c_{0 \text { cp }}-$ средняя скорость на входе в ступень, $\mu / c$;

$c_{\mathrm{p}}$ - изобарная теплоемкость, Джс/(к2·K);

$\bar{G}$ - массовый расход на входе в ступень, $к 2 / c ;$ $\rho_{0}-$ плотность на входе в ступень, $\kappa 2 / \mathrm{M}^{3}$;

$f_{0}$ - площадь сечения входного патрубка, $\mu^{2}$;

$R$ - газовая постоянная, Джс/(кг·K);

$p_{0}$ - статическое давление на входе в ступень, Па.

Поскольку скорость воздуха во всасывающем патрубке (в месте измерения полной температуры) не превышала 15 м/с в данной работе было принято, что $T_{0}^{*}=T_{0}^{*}{ }_{0}^{\prime}$ изм.

Аналогичным образом рассчитывается термодинамическая температура и средняя скорость на выходе из диффузора.

Поскольку течение со вдувом представляет собой процесс с подводом энергии, политропный КПД ступени со вдувом вычисляется с учетом мощности, затрачиваемой на вдув, по формуле:

$$
\eta_{\text {пол }(в \partial)}^{*}=\frac{H_{\text {пол }}^{*} \cdot \bar{G}+c_{p}\left(T_{4}^{*}-T_{в \partial}^{*}\right) \cdot \bar{m}_{в \partial}}{N_{i}+N_{в \partial}},
$$

где $H_{n о л}^{*}-$ политропный напор по полным параметрам, Дж/кг;

$T_{4}^{*}$ - полная температура на выходе из диффузора, $K$;
$T_{\text {вд }}^{*} \quad-$ полная температура вдуваемого воздуха, $K$;

$\bar{m}_{\text {вд }}$ - массовый расход вдуваемого

воздуха, кг/c;

$N_{i}$ - потребляемая мощность, $B m$;

$N_{6 д}$ - мощность вдуваемой струи, $\mathrm{Bm}$.

Пренебрегая теплообменом с окружающей средой, потребляемая мощность рассчитывается по формуле:

$$
N_{i}=c_{p} \cdot\left(T_{2}^{*}-T_{0}^{*}\right) \cdot \bar{G}
$$

где $T_{2}^{*}-$ полная температура на выходе из рабочего колеса, $K$.

Из первого закона термодинамики, полная температура за рабочим колесом (с учетом охлаждения основного потока вдуваемым), равна:

$$
T_{2}^{*}=T_{4}^{*}+\frac{\bar{m}_{\text {в }}}{\bar{G}}\left(T_{4}^{*}-T_{\text {в }}^{*}\right),
$$

Пренебрегая внешним теплообменом, а также поскольку скорость в нагнетательном патрубке не превышала $15 \mathrm{M} / \mathrm{c}$, в работе принято, что $T_{4}^{*}=T_{K}^{*}=T^{*}$ Киз.м.

Мощность струи определяется по формуле:

$$
N_{\text {вд }}=\bar{m}_{\theta \partial} \cdot \frac{c_{\theta \partial}^{2}}{2},
$$

где $c_{в д}-$ скорость вдуваемого воздуха, $\mu / c$.

Скорость вдуваемого воздуха определялась из уравнения массового расхода.

Для оценки эффективности работы диффузора используются коэффициент восстановления статического давления $C_{p}$ и коэффициент потерь полного давления $\zeta$ :

$$
\begin{gathered}
C_{\mathrm{p}}=\frac{p_{4}-p_{3}}{p_{3 c p}^{*}-p_{3}} \\
\zeta=\frac{p_{3 c p}^{*}-p_{4 c p}^{*}}{p_{3 c p}^{*}-p_{3}} .
\end{gathered}
$$

где $p^{*}{ }_{3 c p}-$ осредненное полное давление на входе в диффузор, $П а$;

$p_{3}$ - статическое давление на входе в диффузор, Па;

$p_{4 c p}^{*}$ осредненное полное давление на выходе из диффузора, Па;

$p_{4}$ - статическое давление на выходе из диффузора, Па.

При обработке экспериментальных данных для осреднения параметров потока использовалась методика, изложенная в [8]. 


\section{IV. КОНТРОЛЬНЫЕ СЕЧЕНИЯ И ИЗМЕРЯ- ЕМЫЕ ПАРАМЕТРЫ}

Для получения суммарных газодинамических характеристик ступени и БЛД, а также для определения структуры течения в диффузоре были выбраны следующие контрольные сечения:

- Н-H - сечение, расположенное во входном участке всасывающего трубопровода.

- 0-0 - сечение, расположенное на входе в $\mathrm{PK}$

- 3-3 - сечение на входе в БЛД. Диаметр, на котором расположено это сечение был выбран в соответствии с рекомендациями [8] и был равен $D_{3}=1,05 D_{2}$;

- 3_1 ... 3_6 - сечения по диаметру диффузора, расположенные соответственно на относительных диаметрах 1,$17 ; 1,29 ; 1,41$; 1,$53 ; 1,65 ; 1,77$.

- 4-4 - сечение на выходе из БЛД $\left(D_{4}=1,9 D_{2}\right)$;

- К-К - сечение, расположенное за улиткой в нагнетательном патрубке.

В сечении $H$ - $H$ определялась полная температура воздуха на входе в ступень. Для измерения температуры использовался ртутный термометр ТЛ-4-Б2 ГОСТ 28498-90 с диапазоном измерения $0 \ldots .55^{0} \mathrm{C}$ и ценой деления $0,1^{0} \mathrm{C}$.

В сечении 0-0 измерялись полные и статические давления, а также производился дублирующий замер температуры перед рабочим колесом. Статическое давление измерялось в четырех точках, равномерно расположенных по окружности на внешней стенке входного патрубка. Полные давления измерялись с помощью трубки полного давления (ТПД). В ходе наладочных испытаний поле полных давлений определялось путем траверсирования канала в шести точках по радиусу входного патрубка, при основных испытаниях измерения проводились только по середине канала. Температура измерялась с помощью термометра сопротивления РТ100.

В сечениях 3-3; 3_1; 3_2; 3_3; 3_4; 3_5; 3_6; 4-4 измерялись полные и статические давления, а также направление потока. Полные давление и направления потока измерялись трехканальным аэродинамическим зондом. Зонд выполнен с диаметром носика 2,5 мм, приемными отверстиями диаметром 0,3 мм и углом между центральным и боковым отверстиями $15^{0}$. Для данной конструкции зонда угол нечувствительности к скосу потока при измерении полного давления равен $15^{0}$ [8]. Абсолютная погрешность измерения угла потока не превышает $0,5^{0}$. Для измерения статического давления по диаметру на стенке диффузора со стороны покрывного диска РК были выполнены приемные отверстия диаметром 1 мм в соответствии с рекомендациями [8]. Регистрирующими приборами при измерении давлений являлись Uобразные манометры, смонтированные на общем пьезометрическом щите. Расположение точек из- мерения в радиальной плоскости, а также схема траверсирования потока по ширине БЛД были выбраны по результатам наладочных испытаний.

В сечении $K-K$ измерялась полная температура воздуха на выходе из ступени. Измерения производились с помощью ртутного термометра ТЛ4-Б2 ГОСТ 28498-90 с диапазоном измерения $0 \ldots 55^{0} \mathrm{C}$ и ценой деления $0,1^{\circ} \mathrm{C}$. В качестве дублирующего прибора для измерения температуры использовался термометр сопротивления РТ100.

Частота вращения ротора компрессора определялась с помощью комплекта 3300 «Bently Nevada» с погрешностью не более $0,2 \%$.

Объемный расход вдуваемого воздуха измерялся с помощью двух ротаметров KROHNE H250/RR/M9/ESK-Ex, установленных на каждой из подводящих линий, с верхним пределом измерения 7 нм $^{3} /$ мин и максимальной погрешностью $\pm 0,2 \mathrm{mм}^{3} /$ мин. Температура вдуваемого воздуха измерялась контактным способом при помощи хромельалюмелевых термопар. Для определения давления вдуваемого воздуха на каждом из подводящих трубопроводов был установлен манометр образцовый кл.т. 0,4 и верхним пределом измере-

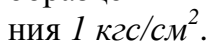

\section{V. ПРОВЕДЕНИЕ ЭКСПЕРИМЕНТАЛЬНЫХ ИССЛЕДОВАНИЙ. РЕЗУ ЛЬТАТЫ НАЛА- ДОЧНЫХ ИСПЫТАНИЙ}

Экспериментальные исследования проводились на модельных оборотах, обеспечивающих постоянное значение числа Маха. При испытаниях контролировалось, чтобы отклонение частоты вращения от расчетного значения было в пределах \pm $2 \%$.

Для определения диапазона работы ступени по производительности, после запуска стенда при полностью открытой заслонке, измерялся перепад давления на расходомерной диафрагме $\left(\Delta p_{\text {д } \max }\right)$, соответствующий максимально возможной производительности ( $\left.\bar{V}_{\max }\right)$. Затем, прикрывая задвижку до возникновения предпомпажных колебаний давления на диафрагме, определялся перепад давления $\left(\Delta p_{\text {д помп }}\right)$, соответствующих предпомпажной производительности $\left(\bar{V}_{\text {поми }}\right)$. Амплитуда колебаний перепада давления на диафрагме, соответствующая предпомпажной производительности, определялась в ходе наладочных испытаний по возникновению характерных звуковых колебаний.

Характеристики ступени и диффузора определялись в шести точках по производительности. Время прогрева компрессора до выхода на установившийся режим составляло примерно $30 \ldots 40$ минут. Установившимся считался режим, при котором не изменялась разность температур воздуха на нагнетании и всасывании.

Для выявления и учета неравномерности потока во входном патрубке и по ширине диффузора, а также для определения влияния выходного устройства на окружную симметрию потока в 
БЛД, перед началом основных испытаний были проведены наладочные.

Прежде всего, были измерены эпюры скоростей во входном патрубке. Анализ результатов траверсирования потока показал, что «форма» эпюр скоростей слабо зависит от режима работы компрессора. Поэтому в дальнейшем полные давления измерялись лишь посередине канала, а неравномерность поля скоростей учитывалась с помощью поправочного коэффициента.

Для выявления влияния выходного устройства на окружную симметрию потока было измерено распределение статических давлений по окружности на входе и выходе из диффузора. Как показали результаты измерений, поток на входе и на выходе из диффузора в области расположения языка сборной камеры имеет неравномерное распределение статических давлений в окружном направлении. Полученные результаты позволили выбрать схему измерения параметров потока в БЛД, при которой влияние выходного устройства было бы наименьшим. Результаты наладочных испытаний подробно изложены в [9].

\section{VI. ОЦЕНКА ПОГРЕШНОСТЕЙ ЭКСПЕРИ- MEHTA}

Поскольку вероятность того, что погрешности прямых однократных измерений величин $x_{1}, x_{2}, \ldots$, $x_{n}$ будут одного знака и одновременно будут иметь максимальные значения, практически равна нулю, при оценке точности результата измерений в данной работе производилось квадратичное суммирование по формуле [10]:

$\Delta y=\sqrt{\left(\frac{\partial y}{\partial x_{1}} \cdot \Delta x_{1}\right)^{2}+\left(\frac{\partial y}{\partial x_{2}} \cdot \Delta x_{2}\right)^{2}+\ldots+\left(\frac{\partial y}{\partial x_{n}} \cdot \Delta x_{n}\right)^{2}}$

где $\Delta x_{1}, \Delta x_{2}, \ldots \Delta x_{n}$ - абсолютные погрешности измеренных величин.

Относительная погрешность определения величины рассчитывается по формуле:

$$
\delta(y)=\frac{\Delta y}{y}
$$

Абсолютные погрешности непосредственно измеряемых величин определены на основании классов точности применявшихся измерительных приборов и имеющихся литературных данных [8]

Результаты расчета абсолютных и относительных погрешностей вычисляемых величин приведены в таблице 1. Расчет произведен для оптимального режима работы ступени (режима с максимальным значением политропного КПД). При определении абсолютных погрешностей не учитывались погрешности для справочных величин.
Таблица 1 - Средние погрешности вычисляемых величин

\begin{tabular}{|l|c|l|}
\hline \multicolumn{1}{|c|}{ Вычисляемый параметр } & $\pm \Delta y$ & $\pm \delta y, \%$ \\
\hline $\begin{array}{l}\text { Условный коэффициент рас- } \\
\text { хода } \Phi_{0}\end{array}$ & $7,0 \cdot 10^{-4}$ & 1,6 \\
\hline $\begin{array}{l}\text { Политропный КПД по пол- } \\
\text { ным параметрам } \eta_{\text {пол }}\end{array}$ & $1,6 \%$ & 1,9 \\
\hline $\begin{array}{l}\text { Коэффициент политропного } \\
\text { напора по полным парамет- } \\
\text { рам } \psi^{*} \text { пол }\end{array}$ & 0,008 & 1,7 \\
\hline $\begin{array}{l}\text { Политропный КПД по пол- } \\
\text { ным параметрам с учетом } \\
\text { вдува } \eta^{*} \text { пол(вд) }\end{array}$ & $2,0 \%$ & 2,5 \\
\hline $\begin{array}{l}\text { Коэффициент потерь полного } \\
\text { давления } \zeta\end{array}$ & 0,004 & 2,3 \\
\hline $\begin{array}{l}\text { Коэффициент восстановления } \\
\text { статического давления } C_{p}\end{array}$ & 0,005 & 0,7 \\
\hline
\end{tabular}

Из таблицы видно, что погрешность определения основных параметров соответствует современным требованиям и целям эксперимента.

\section{VII. ЗАКЛЮЧЕНИЕ}

Приведенные материалы позволяют сделать следующие выводы:

- разработана экспериментальная модель, позволяющая проводить исследования по влиянию вдува на характеристики и структуру течения в безлопаточном диффузоре, а также ступени в целом;

- разработана методика проведения испытаний, включающая в себя схемы измерений и методику обработки опытных данных;

- расчет погрешностей показал, что применяемая методика экспериментального исследования и методика обработки результатов эксперимента обеспечивает получение достоверных экспериментальных данных, с допустимой для газодинамических исследований точностью.

\section{ЛИТЕРАТУРА}

1. Jansen, W. 1964. Rotating Stall in a Radial Vaneless Diffuser, J. Basic. Eng., Vol.86: pp. 750758.

2. Senoo, Y., Kinoshita, Y. 1977. Influence of Inlet Flow Conditions and Geometries of Centrifugal Vaneless Diffusers on Critical Flow Angle for Reverse Flow, J. Fluids Eng., Vol. 99: pp. 98-103.

3. Измайлов, Р. А. Численное моделирование нестационарного течения в ступени центробежного компрессора $[$ Текст]/Р. А. Измайлов, Х. Д. Лопулалан, Г. С. Норимарна // Компрессорная техника и пневматика. - 2011. - № 5. - С. 10-15.

4. Nelson, E. B., Paduano, J. D., and Epstein, A. H. 2000. Active Stabilization of Surge in an Axial Centrifugal Turboshaft Engine, ASME J. Turbomach., Vol. 122: pp. 485-493.

5. Stein, A., Niazi, S., Sankar, L. N. 2000. Computational Analysis of Stall and Separation Control in 
Centrifugal Compressors, Journal of Propulsion and Power, Vol. 16, No. 1: pp. 65-71.

6. Spakovszky, Z. S., Weigle, H. J., Paduano, J. D., et al. 1999. Rotating Stall Control in a High-Speed Stage with Inlet Distortion: Part I - Radial Distortion, ASME J. Turbomachinery, Vol. 121: pp. 510-516.

7. Skoch, G. J. 2003. Experimental Investigation of Centrifugal Compressor Stabilization Techniques, ASME J. Turbomachinery, Vol. 125: pp. 704-713.

8. Галеркин Ю.Б. Методы исследования центробежных компрессорных машин / Галеркин Ю. Б., Рекстин Ф.С. - Л.: Машиностроение, 1969. - 304 с. 9. Калинкевич Н.В., Щербаков О.Н. Экспериментальное исследование течения газа в безлопаточном диффузоре центробежного компрессора // Наукові праці ДонНТУ. Серія гірничоелектромеханічна. - 2011. - Вип. 22(195). - С.88100

10. Преображенский В.В. Теплотехнические измерения и приборы. - М.: Энергия, 1978. - 704c.

\section{REFERENCES}

1. Jansen, W. 1964. Rotating Stall in a Radial Vaneless Diffuser, J. Basic. Eng., Vol.86: pp. 750758.

2. Senoo, Y., Kinoshita, Y. 1977. Influence of Inlet Flow Conditions and Geometries of Centrifugal Vaneless Diffusers on Critical Flow Angle for Reverse Flow, J. Fluids Eng., Vol. 99: pp. 98-103.

3. Izmailov, R. A., Lopulalan, H. D., Norimarna,

G. S. 2011. Chislennoe modellirovanie nestacionar- nogo techeniya v stupeni centrobezhnogo compressora [Numerical modeling of unsteady flow in a centrifugal compressor's stage (in Russian)], J. Compressornaya technika i pnevmaticka, Vol.5: pp. 10-15

4. Nelson, E. B., Paduano, J. D., and Epstein, A. H. 2000. Active Stabilization of Surge in an Axial Centrifugal Turboshaft Engine, ASME J. Turbomach., Vol. 122: pp. 485-493.

5. Stein, A., Niazi, S., Sankar, L. N. 2000. Computational Analysis of Stall and Separation Control in Centrifugal Compressors, Journal of Propulsion and Power, Vol. 16, No. 1: pp. 65-71.

Spakovszky, Z. S., Weigle, H. J., Paduano, J. D., et al. 1999. Rotating Stall Control in a High-Speed Stage with Inlet Distortion: Part I - Radial Distortion, ASME J. Turbomachinery, Vol. 121: pp. 510-516.

6. Skoch, G. J. 2003. Experimental Investigation of Centrifugal Compressor Stabilization Techniques, ASME J. Turbomachinery, Vol. 125: pp. 704-713.

7. Galerkin Y.B., Rekstin F.S. 1969. Metodi issledovaniya centrobezhnih compressornih mashin [Methods of investigation of centrifugal compressor machines (in Russian)]. Leningrad; Mashinostroenie, 304 p.

8. Kalinkevych, M., Shcherbakov, O. 2011. Experimental'noe issledovanie techeniya gaza $\mathrm{V}$ stupeni centrobezhnogo compressora [Experimental investigation of gas flow in the vaneless diffuser of centrifugal compressor (in Russian)], DonNTU Herald, Vol. 22: pp. 88-100.

9. Preobrazhenskiy V.V. 1978. Teplotehnicheskie izmereniya i pribory [Thermotechnics measurements and devices (in Russian)], Moscow; Energiya, 704 p.

\section{PROCEDURE OF EXPERIMENTAL INVESTIGATION OF INJECTION IN THE VANELESS DIF- FUSER OF CENTRIFUGAL COMPRESSOR}

Procedure of experimental investigation of injection in the vaneless diffuser of centrifugal compressor' stage is presented in the paper. The motivation for the present work was to improve the stable flow range of centrifugal compressors by modifying flow in the vaneless diffuser. Presented article has a practical interest. Original experimental model to investigate impact of injection on stable flow range and stage characteristics has been designed and is presented in the paper. The designed model allows to inject air through both the hub and shroud surfaces of the diffuser. An external source is used for the injection air supply. The measuring system and devices are also described in the paper. Analysis of averaged errors has shown that presented experimental procedure and measuring system allow to receive accurate experimental results.

Keywords: Centrifugal compressor - Experimental investigation - Vaneless diffuser - Extending of the stable operating range.

Отримана в редакції 07.02.2014, прийнята до друку 04.03.2014 